\title{
Comparison of Au(III) Sorption on Amine-Modified Silica (AMS) and Quaternary Amine- Modified Silica (QAMS): A Thermodynamic and Kinetics Study
}

\author{
Ngatijo $^{1,}$, Rahmat Basuki ${ }^{1}$, Nuryono $^{2}$, and Bambang Rusdiarso ${ }^{2}$ \\ ${ }^{1}$ Department of Chemistry, Faculty of Science and Technology, University of Jambi, \\ Jl. Jambi-Muara Bulian km 15, Mendalo, Jambi 36361, Indonesia \\ ${ }^{2}$ Department of Chemistry, Faculty of Mathematics and Natural Sciences, Universitas Gadjah Mada, \\ Sekip Utara, Yogyakarta 55281, Indonesia
}

${ }^{*}$ Corresponding author:

tel: $+62-82185813527$

email: tijo52@yahoo.co.id

Received: March 8, 2018

Accepted: May 15, 2018

DOI: $10.22146 /$ ijc. 33758

\begin{abstract}
Amine-Modified Silica (AMS) and Quaternary Amine-Modified Silica (QAMS) has been synthesized through the sol-gel process for adsorption Au(III) in aqueous solution. The aim of this work was to compare the effect of addition three methyl group of AMS to form QAMS on its character, thermodynamics and kinetics parameter of sorption of $A u(I I I)$ in aqueous solution. Characterizations performed by FT-IR, XRD, SEM and BET analyzer. Sorption study was carried out in a batch system under the various experimental conditions including the effect of medium acidity, a variation of $A u(I I I)$ concentration (thermodynamics study), and variation of contact time (kinetics study). Optimum $p H$ of sorption Au(III) on AMS was 3 and shift into 5 on QAMS. Thermodynamics sorption study by Langmuir isotherm models indicates that there was an increase of sorption capacity from $37.94 \mathrm{mg} / \mathrm{g}$ (AMS) to $74.47 \mathrm{mg} / \mathrm{g}$ (QAMS). Kinetics sorption studies by Lagergren, Ho, and RBS models indicate that the sorption Au(III) in this research fitted well with the RBS models. The addition of 3 methyl group also increased the sorption rate of Au(III) on QAMS $\left(k_{a}=77.29 \mathrm{~min}^{-1}(\mathrm{~mole} / \mathrm{L})^{-1}\right)$ over AMS $\left(k_{a}=69.22 \mathrm{~min}^{-1}(\text { mole } / L)^{-1}\right)$ and reinforce the electrostatic interaction between active site of QAMS.
\end{abstract}

Keywords: sorption; AMS; QAMS; kinetics study; thermodynamic study

\section{- INTRODUCTION}

Rare, precious and strategic metals, especially gold are very important. Commercial value and toxicity are the two properties of these metals which warrant their recovery from solution. Gold is introduced into the water from leach mining and waste solution from metal finishing industries [1]. Gold is widely used in many fields such as catalysts in various chemical processes, in electrical and electronic industries, in medicine and jewelry [2]. Growing demand for gold is of great economic interest to the recovery of this metal from aqueous and waste solutions as mineral stocks have started to decline [3]. There are several methods, such as ion-exchange, liquid-liquid extraction, membrane filtration, and sorption, available in the literature for the removal of precious metals from aqueous solutions [4].
Of major interest, sorption process can be defined as a surface phenomenon by which a multicomponent fluid (gas or liquid) mixture is attracted to the surface of solids adsorbents and forms attachment via the physical or chemical bond. Sorption process is recognized as the most efficient, promising and widely used fundamental approach for the recovery of precious metals, mainly hinges on its simplicity, economically viable, technically feasible and socially acceptable [5]. In the development of adsorbent, silica gel is very important material because it can be used as a support material possesses some advantages such as high mechanical and chemical properties, high porosity, large surface, no swelling, resistant in the microbial attack, resistant in decay radiation and heat-stable [6]. In addition, chelating agents can be easily chemically bonded to the support, 
that affording higher stability. Silica contains functional groups of silanol (-Si-OH) and siloxane (-Si-O-Si-) on the surface which is allowing to be modified with active groups specific to certain targets [7].

In order to organize, establish and understand an adequate design model for the sorption process from aqueous media, isotherms, kinetics, and thermodynamic studies are essential basic prerequisites. In perspective, equilibrium relationship, known as sorption isotherm, describes how sorbate interacts with the sorbent materials, and thus are critical for optimization of the sorption mechanism pathways, expression of the surface properties and capacities of sorbent. The mathematical association which establishes a significant role towards the modeling analysis, operational design and applicable practice of the sorption systems is normally represented by plotting a graph between solid-phase and its residual concentration [8]. One of the well-known sorption isotherm basic approaches was Langmuir monolayer sorption [9]. From the same approach, Rusdiarso et al. [10] derive kinetics equation -known as RBS kinetics model- which is expected can relate to the isotherm sorption (Langmuir) parameters and kinetic parameters.

In the endeavor to explore novel adsorbent, the development of silica was studied by many researchers for many past decades. In present work, silica was modified by amines synthesized to adsorb precious metal ion, $\mathrm{Au}(\mathrm{III})$. The privilege of these materials (AMS and QAMS) has been compared with the previous research. The comparison of thermodynamic data (Langmuir [9] and Freundlich isotherm [11]) and kinetics study (Lagergren [12], Ho [13], and RBS kinetics model [10]) of these AMS and QAMS was criticized in this paper.

\section{- EXPERIMENTAL SECTION}

\section{Materials}

Materials used for preparing the sorbent were sodium hydroxide $(\mathrm{NaOH}), 3$-aminopropilmexyxilane (3-APTMS), hydrochloric acid $(\mathrm{HCl})$, dimethylforma mide (DMF), acetonitrile, toluene, sodium bicarbonate, and methyl iodide. All reagents were analytical grade purchased by Merck. Co, Germany without further purification. A solution of $\mathrm{Au}(\mathrm{III})$ was prepared in our laboratory by dissolving gold in an aquaregia solution. Rice husk raw material was taken from Gunung Kidul, Yogyakarta.

\section{Instrumentation}

The functional group of materials was identified with Fourier Transform Infra-Red (FTIR) spectrophotometer Shimadzu IR prestige 21. The crystal structure was analyzed using Shimadzu X-ray diffraction (XRD) and using $\mathrm{Cu} \mathrm{Ka}$ radiation $(\lambda=1.5406 \AA)$ operated at $40 \mathrm{kV}$ and $30 \mathrm{~mA}$. The surface morphology and particle size were examined using a JEOL SSM-6510 LA Scanning Electron Microscopy (SEM). Specific surface area analysis was conducted by Surface Area Analyzer (SSA) BET Quantum 600. The determination of metal ion concentrations was performed with a Flame Atomic Absorption Spectrophotometer (FAAS, Shimadzu AA 6650).

\section{Procedure}

\section{Synthesis of AMS and QAMS}

Synthesis QAMS was conducted by sol-gel process from rice husk raw material. Rice husk ash was treated with $\mathrm{NaOH} 2 \mathrm{M}$, followed by boiling and stirring for $4 \mathrm{~h}$ to generate red filtrate of $\mathrm{Na}$-Silicate. The $\mathrm{Na}$-Silicate was then dissolved in distilled water to obtain a highquality $\mathrm{Na}$-Silicate solution. $\mathrm{HCl}$ was then slowly added to the hydrated Na-Silicate to obtain Silica Gel (SG). Into another $100 \mathrm{~mL}$ of $\mathrm{Na}$-Silicate solution, 3-aminopropil mexyxilane (3-APTMS) was added followed by adding of $\mathrm{HCl} 2 \mathrm{M}$ dropwise until $\mathrm{pH}$ reaches 5 to generate sol of AMS. Sol of AMS then aged for $3 \times 24 \mathrm{~h}$ until the gel was formed. The gel was then washed with distilled water until free of acid (neutral). This product (AMS) was then filtered, and the filtrate (gel) dried at $60^{\circ} \mathrm{C}$ for $6 \mathrm{~h}$.

QAMS was synthesized by refluxing the mixture of $12 \mathrm{~g}$ of AMS, $20 \mathrm{~mL}$ of DMF, $20 \mathrm{~mL}$ of acetonitrile, $20 \mathrm{~mL}$ of toluene, and $2 \mathrm{~mL}$ of methyl iodide at $70^{\circ} \mathrm{C}$ for $6 \mathrm{~h}$. Simultaneously, $4 \mathrm{~mL}$ of methyl iodide was added to it drop wisely. The mixture was then filtered, and the filtrate was washed in sequence with distilled water, $\mathrm{NaHCO}_{3} 2 \%(\mathrm{w} / \mathrm{v})$, and distilled water. The filtrate was dried at $80^{\circ} \mathrm{C}$ for $6 \mathrm{~h}$ to form QAMS. 


\section{Effect of medium acidity}

At first, a series of $20 \mathrm{~mL}$ of $\mathrm{Au}(\mathrm{III}) 100 \mathrm{mg} / \mathrm{L}$ was prepared and their acidity was adjusted to $2.0,3.0,4.0,5.0$, and 6.0 by adding $\mathrm{HCl} 0.1 \mathrm{M}$ solution. Into every $\mathrm{Au}(\mathrm{III})$ solution, $0.1 \mathrm{~g}$ of the sorbent was poured and then stirred for $2 \mathrm{~h}$. After filtering through $2.5 \mu \mathrm{m}$ hole membrane filter, the concentration of $\mathrm{Au}$ (III) in the supernatant was analyzed by using FAAS. Sample and blank solutions were analyzed under same conditions. The amount of sorbed $\mathrm{Au}$ (III) was considered to be the difference between the initial and the remaining amount of the reacting solution each time a sample was analyzed.

\section{Thermodynamic study}

The thermodynamic study (sorption isotherm) experiments were carried out using a batch type reactor using $50 \mathrm{~mL}$ Erlenmeyer in a water bath at $25 \pm 0.01{ }^{\circ} \mathrm{C}$. As much as $0.1 \mathrm{~g}$ of sorbents was interacted with and stirred in $20 \mathrm{~mL}$ of solutions containing the various concentrations of $\mathrm{Au}$ (III) (10, 25, 50, 100, 150, 200 and $250 \mathrm{mg} / \mathrm{L}$ ) at the optimum $\mathrm{pH}$ for $2 \mathrm{~h}$ and then aged for $24 \mathrm{~h}$. After separating the supernatants, the concentration of $\mathrm{Au}$ (III) in the supernatant was determined by FAAS. Under the same condition with the sample solution, the blank solution was also analyzed.

\section{Kinetics study}

The kinetics experiments also were carried out using a batch type reactor using $50 \mathrm{~mL}$ Erlenmeyer in a water bath at $25 \pm 0.01{ }^{\circ} \mathrm{C}$. The volume of sorption medium was $20 \mathrm{~mL}$, the initial metal ion concentration was 100 $\mathrm{mg} / \mathrm{L}$, and the acidity was adjusted at the optimum $\mathrm{pH}$. Into each solution, $0.1 \mathrm{~g}$ of the sorbent was added and then stirred continuously at 5, 10, 15, 30, 45, 60 and 120 min. The sample was immediately filtered through 2.5 $\mu \mathrm{m}$ hole filter, and the concentration of $\mathrm{Au}(\mathrm{III})$ in the supernatant was analyzed by using FAAS. Sample and blank solutions were analyzed under the same conditions. The amount of $\mathrm{Au}(\mathrm{III})$ sorbed was considered to be the difference between the initial and the remaining amount in the reacting solution each time a sample was analyzed.

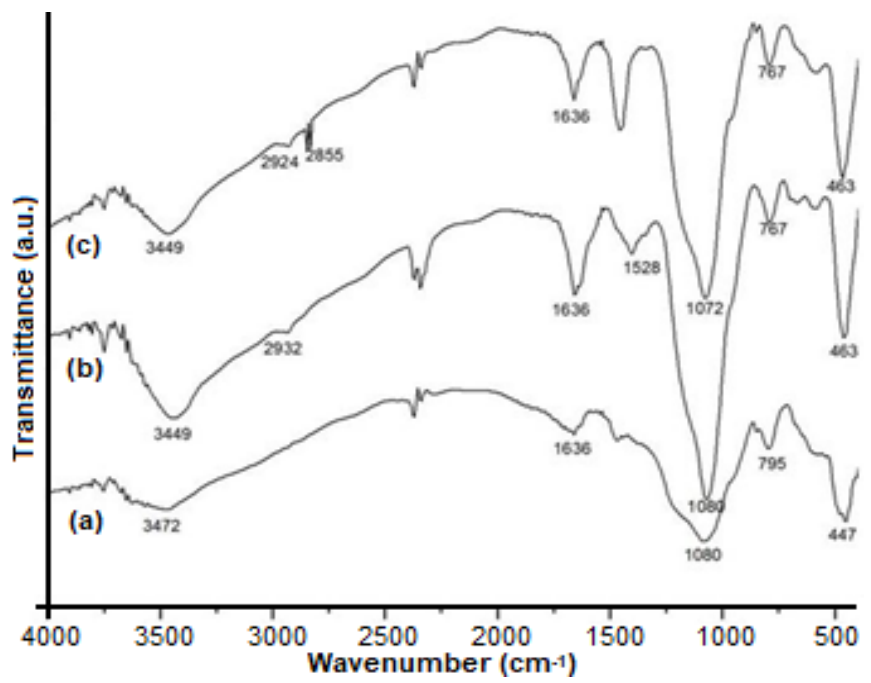

Fig 1. FT-IR spectra of (a) SG, (b) AMS, and (c) QAMS
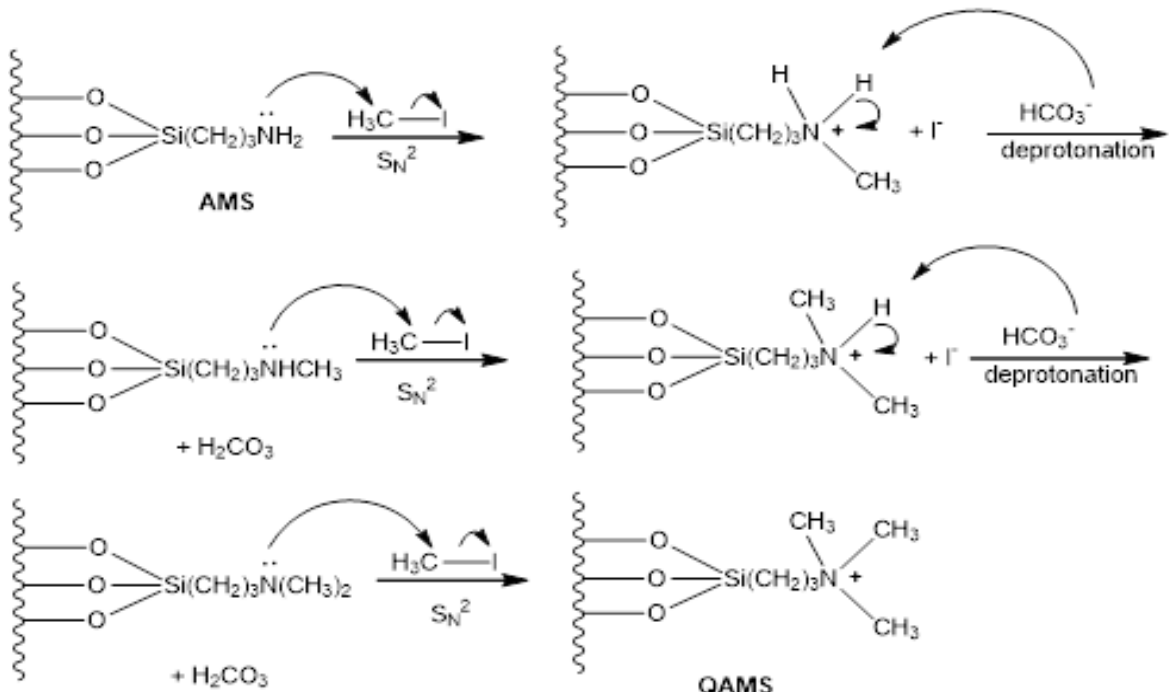

Fig 2. The structure of AMS and QAMS and the proposed mechanism of formation QAMS from AMS 


\section{- RESULTS AND DISCUSSION}

\section{Characterization of Materials}

FT-IR spectra show that the difference between functional groups of SG, AMS, and QAMS can be observed qualitatively (Fig. 1). Characteristic functional group of SG at $447 \mathrm{~cm}^{-1}$ was identified as bend vibration of $\mathrm{Si}-\mathrm{O}$ from siloxane group (Si-O-Si), $1080 \mathrm{~cm}^{-1}$ as asymmetric stretching of $\mathrm{Si}-\mathrm{O}$, and $1636 \mathrm{~cm}^{-1}$ as bend vibration of Si-O from silanol group [14]. Absorption at $1528 \mathrm{~cm}^{-1}$ (bend vibration of $\mathrm{N}-\mathrm{H}$ from $-\mathrm{NH}_{2}$ group) in AMS indicated the AMS still have $-\mathrm{NH}_{2}$ group, however, SG and QAMS do not have this absorbance that indicate there are no $-\mathrm{NH}_{2}$ group in SG and QAMS. Stretching vibration of $\mathrm{C}-\mathrm{H}$ from methyl group at $2855 \mathrm{~cm}^{-1}$ [15] emerged only in QAMS which indicate formed $-\mathrm{CH}_{3}$ at QAMS. The differences between AMS and QAMS was a disappearing peak at $1528 \mathrm{~cm}^{-1}$, and a new emerging peak at $2855 \mathrm{~cm}^{-1}$ in QAMS, indicated the transformation of N$\mathrm{H}$ from $-\mathrm{NH}_{2}$ group to $\left[-\mathrm{N}^{+}\left(\mathrm{CH}_{3}\right)_{3}\right]$. The structure of AMS and QAMS and the proposed mechanism of formation AMS to QAMS can be seen in Fig. 2.

XRD diffractogram of AMS and QAMS show that these all material are non-crystalline (amorphous), and $\mathrm{SiO}_{2}$ character emerges at $2 \theta=20-25^{\circ}$ [16-18]. This condition also reported by Della et al. [19] that there is no significant change in diffractogram peak of incinerating time of rice husk ash to form SG. The diffractogram of SG, AMS, and QAMS shows in Fig. 3. The surface morphology by SEM-EDX analysis before and after methylation of AMS and QAMS shows that the surface morphology of QAMS more heterogenic than AMS. QAMS shows more cavities from methylation process (Fig. 4). From EDX data, AMS only consist of elements $\mathrm{Si}, \mathrm{O}, \mathrm{Na}$, and $\mathrm{N}$. However, in QAMS there is iodium (I) from $\mathrm{CH}_{3} \mathrm{I}$ (Fig. 2) as a residual element of methylation process. The residual iodine from methyl iodide in QAMS (1.09\% (w/w)) higher than AMS (0.23\% (w/w)). Additionally, the percentage of carbon in QAMS higher than AMS, this indicates that methylation occurred on a

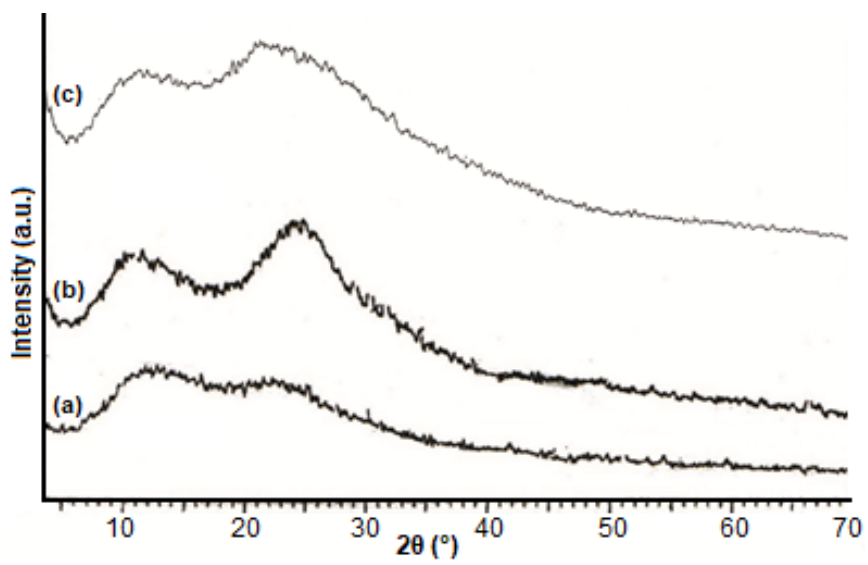

Fig 3. The diffractogram pattern from XRD analysis of (a) SG, (b) AMS, and (c) QAMS
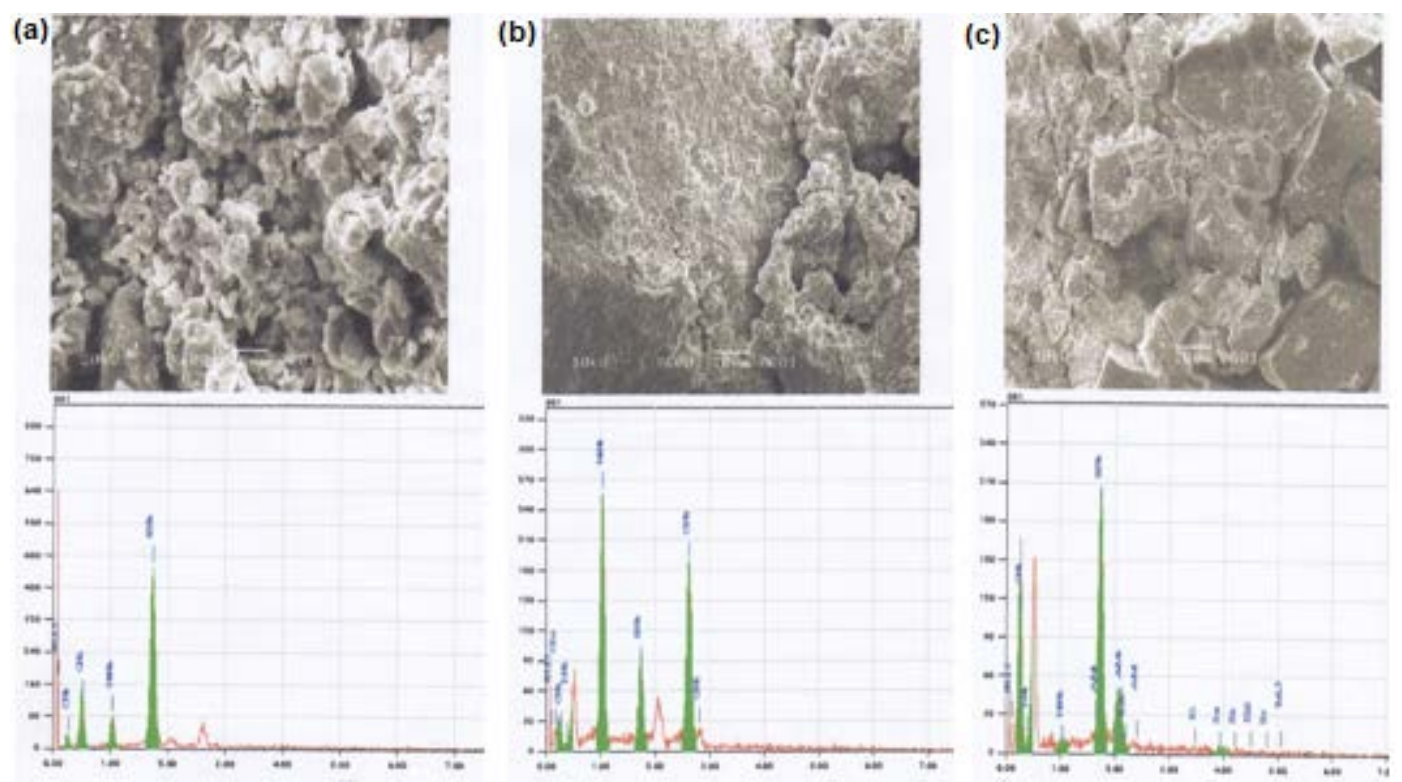

Fig 4. Morphological and elemental analysis by SEM-EDX of (a) SG, (b) AMS, and (c) QAMS 
Table 1. Elemental analysis by EDX of SG, AMS, and QAMS

\begin{tabular}{ccccccc}
\hline \multirow{2}{*}{ Elements } & \multicolumn{2}{c}{ SG } & \multicolumn{2}{c}{ AMS } & \multicolumn{2}{c}{ QAMS } \\
\cline { 2 - 7 } & Mass (\%) & Atom (\%) & Mass (\%) & Atom (\%) & Mass (\%) & Atom (\%) \\
\hline $\mathrm{C}$ & - & - & 37.36 & 19.58 & 50.51 & 63.93 \\
$\mathrm{O}$ & 8.29 & 27.14 & - & - & - & - \\
$\mathrm{N}$ & - & - & 10.28 & 20.97 & 18.78 & 20.34 \\
$\mathrm{Na}$ & - & - & 0.41 & 0.25 & - & - \\
$\mathrm{Si}$ & 91.72 & 72.86 & 32.53 & 32.80 & 28.70 & 15.50 \\
$\mathrm{I}$ & - & - & - & - & 1.90 & 0.23 \\
\hline
\end{tabular}

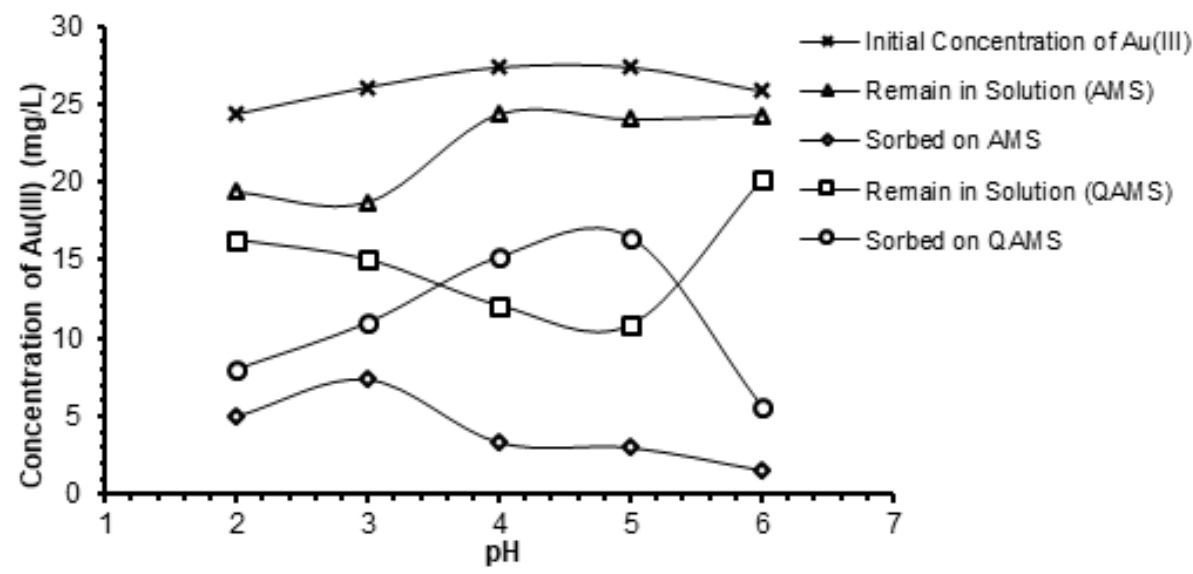

Fig 5. Effect of medium acidity of sorption Au(III) on AMS (red) and QAMS(blue)

quaternary group of carbon. The EDX analysis of SG, AMS, and QAMS was shown in Table 1.

\section{Effect of Medium Acidity}

In acid condition, AMS which have an amino group $\left(-\mathrm{NH}_{2}\right)$ will be protonated to formed $-\mathrm{NH}_{3}{ }^{+}$which will electrostatically interact with $\left[\mathrm{AuCl}_{4}\right]^{-}$. The presence of $\mathrm{Cl}^{-}$would also compete with $\left[\mathrm{AuCl}_{4}\right]^{-}$which caused by the increasing of medium acidity. The optimum $\mathrm{pH}$ of $\mathrm{Au}$ (III) sorption on AMS occurred at $\mathrm{pH}=3$ (Fig. 5). In $\mathrm{pH}$ above 3, sorption $\mathrm{Au}(\mathrm{III})$ decreased dramatically because of the formation of several dominant species in solution, i.e. $\left.[\mathrm{AuOHCl}]_{3}\right]^{-},\left[\mathrm{Au}(\mathrm{OH})_{2} \mathrm{Cl}_{2}\right]^{-}$, and $\mathrm{Au}(\mathrm{OH})_{3}$ [20]. Sorption of $\mathrm{Au}$ (III) on QAMS was affected by solution acidity. Generally, sorption of $\mathrm{Au}$ (III) on QAMS increased by increasing the $\mathrm{pH}$ solution. In $\mathrm{pH}<5$, sorbed $\mathrm{Au}$ (III) was relatively small because of higher concentration of $\mathrm{H}^{+}$ which affect the electrostatic interaction between active site of QAMS, $\left[-\mathrm{N}^{+}\left(\mathrm{CH}_{3}\right)_{3}\right]$ and $\left[\mathrm{AuCl}_{4}\right]^{-}$. The optimum $\mathrm{pH}$ of $\mathrm{Au}$ (III) sorption on QAMS was 5. In $\mathrm{pH}>5$, the concentration of $\mathrm{H}^{+}$ion was relatively small. Oppositely, the concentration of $\mathrm{OH}^{-}$ion was higher and $\mathrm{Au}(\mathrm{OH})_{3}$ was formed which affect the decreasing sorption of $\mathrm{Au}(\mathrm{III})$ on QAMS. The excess of $\mathrm{OH}^{-}$ion also increased the competition between $\left[\mathrm{AuCl}_{4}\right]^{-}$and $\mathrm{OH}^{-}$on the active site of QAMS $\left[-\mathrm{N}^{+}\left(\mathrm{CH}_{3}\right)_{3}\right]$.

\section{Thermodynamics Study}

Thermodynamic study especially determination of capacity and sorption energy of $\mathrm{Au}(\mathrm{III})$ on sorbent (AMS and QAMS) was plotted using Langmuir and Freundlich isotherm models.

Langmuir isotherm model: $\frac{\mathrm{C}}{\mathrm{m}}=\frac{1}{\mathrm{~b}} \mathrm{~K}+\frac{\mathrm{C}}{\mathrm{b}}$

Freundlich isotherm model: $\log m=\log B+\frac{1}{n} \log C$

where $\mathrm{C}$, the equilibrium concentration in solution; $\mathrm{b}$, Langmuir's sorption capacity; K, Langmuir's constant of equilibrium; $\mathrm{m}$, metal sorbed/g sorbent at equilibrium; $B$, Freundlich isotherm capacity and n, constants. 
Langmuir isotherm model can be written derive from this model:

\begin{tabular}{lcccc} 
& $\mathrm{A}$ & $+\mathrm{S}$ & $\underset{\mathrm{k}_{d}}{\stackrel{\mathrm{k}_{a}}{\rightleftarrows}}$ & $\mathrm{A}^{* S}$ \\
At $\mathrm{t}=0$ & $\mathrm{a}=\mathrm{C}_{0}$ & $\mathrm{~b}$ & - \\
Sorbed & $\mathrm{m}$ & $\mathrm{m}$ & $\mathrm{m}$ \\
\hline
\end{tabular}

In equilibrium $a-m=C b-m \quad m$

where $\mathrm{a}=\mathrm{C}_{\mathrm{o}}$ is initial concentration of $\mathrm{A}(\mathrm{mol} / \mathrm{L}) ; \mathrm{m}$ is the amount of A sorbed/g $S$ in equilibrium ( $\mathrm{mol} / \mathrm{g})$; and $\mathrm{a}-\mathrm{m}$ $=\mathrm{C}$ is concentration/remain of $\mathrm{A}$ in equilibrium $(\mathrm{mol} / \mathrm{L})$. The equilibrium constant, $\mathrm{K}$ can be written as:

$\mathrm{K}=\frac{\left[\mathrm{A}^{\star} \mathrm{S}\right]}{[\mathrm{A}][\mathrm{S}]}=\frac{\mathrm{m}}{(\mathrm{b}-\mathrm{m}) \mathrm{C}_{\mathrm{e}}}$

Eq. (1) can be rearranged:

$\mathrm{m}=\frac{\mathrm{KC}_{\mathrm{e}} \mathrm{b}}{1+\mathrm{KC}_{\mathrm{e}}}$

The linear form of Eq. (2) can be written as Eq. (3) that we know as well-known Langmuir isotherm model [9]:

$\frac{\mathrm{C}_{\mathrm{e}}}{\mathrm{m}}=\frac{1}{\mathrm{~Kb}}+\frac{1}{\mathrm{~b}} \mathrm{C}_{\mathrm{e}}$

If it is assumed that the sorption follows the Langmuir isotherm model, the sorption capacity (b) and constant of equilibrium $(\mathrm{K})$ can be calculated respectively

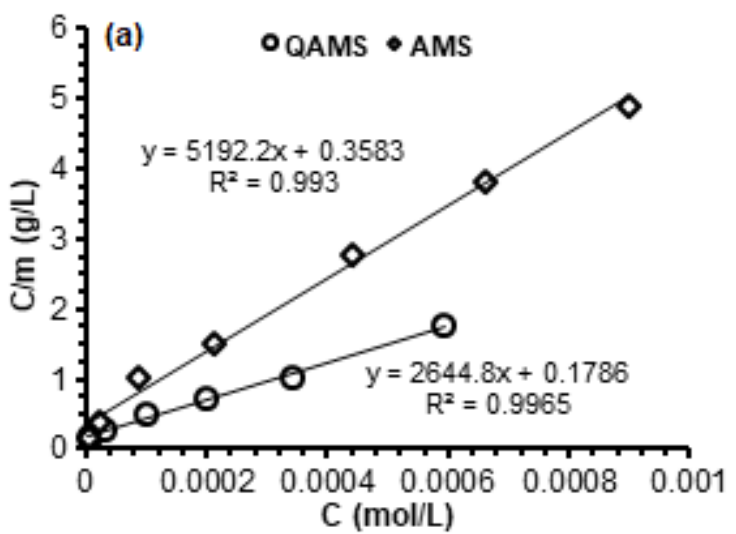

from the slope and intercept of plot between $\mathrm{C} / \mathrm{m}$ and C. If it is assumed that the sorption follows the Freundlich, isotherm model, the sorption capacity (B) can be obtained from the intercept of plot between $\ln \mathrm{m}$ versus $\ln \mathrm{C}$. The application of the two models resulted in the sorption parameters shown in Table 2. Compared to the Freundlich model, the experimental data appeared fitted better in Langmuir isotherm model (Fig. 6). The plot of Langmuir isotherm model of $\mathrm{Au}(\mathrm{III})$ on both AMS and QAMS yielded better linearity $\left(\mathrm{R}^{2} \mathrm{AMS}=0.993\right.$; QAMS $=0.997)$ than Freundlich model $\left(\mathrm{R}^{2}=0.984 ; 0.959\right)$, indicated that the sorption of $\mathrm{Au}(\mathrm{III})$ follows the monolayer models.

The Langmuir isotherm model is designed for monolayer sorption of species on a homogeneous surface with the same sorption energy for all active site regardless of the degree of coverage, while the Freundlich is for multilayer sorption on heterogeneous surface with the frequency of sites associated with free energy of sorption decrease exponentially with the increase of free energy [5]. If we assume $\left[-\mathrm{N}^{+}\left(\mathrm{CH}_{3}\right)_{3}\right]$ is the responsible group for the sorption of metal ions, then the capacity (monolayer or mono-energy) Langmuir sorption may indicate the number of this group.

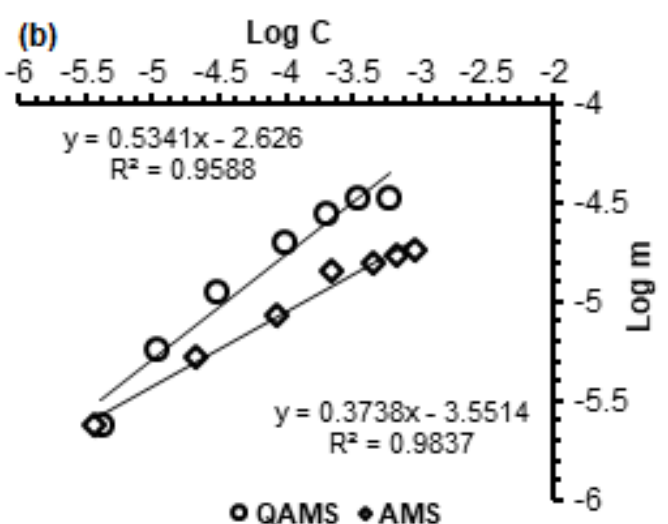

- QAMS • AMS

Fig 6. The linearity of Langmuir (a) and Freundlich isotherm models (b) of $20 \mathrm{~mL} \mathrm{Au}$ (III) $100 \mathrm{mg} / \mathrm{L}$ sorption onto 0.1 g AMS $(\mathrm{pH}=3)$ and 0.1 g QAMS $(\mathrm{pH}=5)$

Table 2. Thermodynamics parameter by Langmuir and Freundlich isotherm models of $\mathrm{Au}(\mathrm{III})$ sorption in $0.1 \mathrm{~g}$ sorbents in $20 \mathrm{~mL}$ series of concentration $\mathrm{Au}(\mathrm{III})$ solutions

\begin{tabular}{lcccccc}
\hline \multirow{2}{*}{ Sorbents } & \multicolumn{3}{c}{ Langmuir } & \multicolumn{3}{c}{ Freundlich } \\
\cline { 2 - 7 } & $\mathrm{b}(\mathrm{mg} / \mathrm{g})$ & $\mathrm{K}(\text { mole } / \mathrm{L})^{-1}$ & $\mathrm{R}^{2}$ & $\mathrm{~B}(\mathrm{mg} / \mathrm{g})$ & $\mathrm{n}$ & $\mathrm{R}^{2}$ \\
\hline AMS & 37.94 & 14491 & 0.993 & 55.34 & 2.68 & 0.984 \\
QAMS & 74.47 & 14809 & 0.997 & 466.02 & 1.84 & 0.959 \\
\hline
\end{tabular}

Ngatijo et al. 
Table 3. Specific surface area, total pore volume, and pore diameter of SG, AMS, and QAMS by SAA using gas nitrogen

\begin{tabular}{cccc}
\hline Materials & $\begin{array}{c}\text { Specific surface } \\
\text { area }\left(\mathrm{m}^{2} \mathrm{~g}^{-1}\right)\end{array}$ & $\begin{array}{c}\text { Total pore volume } \\
\left(\mathrm{mL} \mathrm{g}^{-1}\right)\end{array}$ & $\begin{array}{c}\text { Pore diameter } \\
(\AA)\end{array}$ \\
\hline SG & 103.505 & 0.092 & 1.7826 \\
AMS & 98.410 & 0.080 & 1.6798 \\
QAMS & 164.682 & 0.804 & 9.7623 \\
\hline
\end{tabular}

It was proved by better linearity of Langmuir isotherm model than Freundlich because metal ions will occupy the active site that has the strongest interaction first and then followed by the occupation of metal ions with lower energy active site. Whereas, capacity (multilayer or multienergy) indicates the Freundlich sorption capacity $\left[-\mathrm{N}^{+}\left(\mathrm{CH}_{3}\right)_{3}\right]$ and another active site together. Interactions occurred allegedly as electrostatic forces between the metal ions with active sites of QAMS.

Determining specific surface area, total pore volume, and pore diameter of SG, AMS, and QAMS using Surface Area Analyzer (SAA) can be seen in Table 3. From the table, AMS relatively had specific surface area and smaller total pore volume than SG. It can be deduced that SG was partially covered by 3-APTMS after modification SG to form AMS. SAA shows that surface area of QAMS increase from $98.41 \mathrm{~m}^{2} \mathrm{~g}^{-1}$ (AMS) to $164.68 \mathrm{~m}^{2} \mathrm{~g}^{-1}$ (QAMS). The main modification in AMS formation was to increase the chain of the alkyl group (propyl) with amino $\left(-\mathrm{NH}_{2}\right)$ end and to change the silanol $(-\mathrm{Si}-\mathrm{OH})$ to the siloxane (-Si-O-Si-). This propyl $\left(-\left(\mathrm{CH}_{2}\right)_{3}{ }^{-}\right)$has an important role as support to $-\mathrm{NH}_{2}$ which have lone pair electron as a donor to form complex compound to $\mathrm{Au}$ (III) by a covalent coordination bond.

The result of this modification was proved by Langmuir isotherm model that monolayer sorption capacity of QAMS (74.47 $\mathrm{mg} \mathrm{g}^{-1}$ ) was higher than AMS $\left(37.94 \mathrm{mg} \mathrm{g}^{-1}\right)$. The increase of sorption capacity can be explained by the positive charge of QAMS $\left(\left[-\mathrm{N}^{+}\left(\mathrm{CH}_{3}\right)_{3}\right]\right)$ that lead the electrostatic interaction with a negative charge of $\left[\mathrm{AuCl}_{4}\right]^{-}$. Furthermore, three methyl group was a donating electron group that promotes lone pair electron given to $\mathrm{Au}(\mathrm{III})$. This material, QAMS also had higher sorption capacity of $\mathrm{Au}(\mathrm{III})$ compared to MNSA (17.7 $\mathrm{mg} \mathrm{g}^{-1}$ ) [2], LMCC (70.34 $\left.\mathrm{mg} \mathrm{g}^{-1}\right)$ [21], $\mathrm{SiO}_{2}$-arg

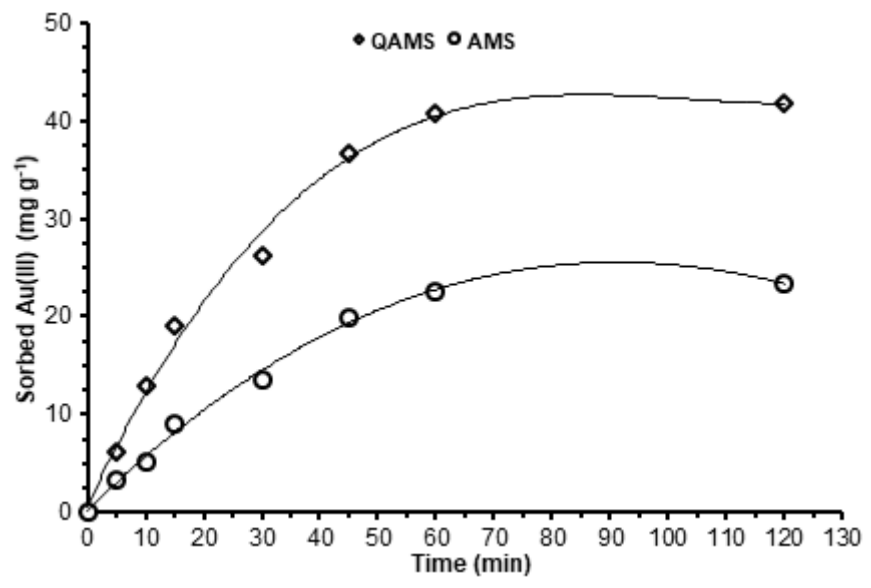

Fig 7. Sorption profile as function of time of $20 \mathrm{~mL}$ $\mathrm{Au}$ (III) $100 \mathrm{mg} / \mathrm{L}$ onto (a) $0.1 \mathrm{~g}$ QAMS in $\mathrm{pH} 5$ and (b) $0.1 \mathrm{~g}$ AMS in $\mathrm{pH} 3$ at $27^{\circ} \mathrm{C}, 1 \mathrm{~atm}$

(52.79 $\mathrm{mg} \mathrm{g}^{-1}$ ) [6], and 4-amino-4-nitro azobenzene modified chitosan $\left(69.93 \mathrm{mg} \mathrm{g}^{-1}\right)$ [22] but still had a lower sorption capacity compared to GMCCR (169.98) [2].

\section{Kinetics Study}

The sorption profile of $\mathrm{Au}(\mathrm{III})$ as a function of interaction time is presented in Fig. 7. The sorption of $\mathrm{Au}(\mathrm{III})$ was initially rapid and then went slower. The initial rapid sorption was observed for the first $40 \mathrm{~min}$ and then went slower after $60 \mathrm{~min}$. After $120 \mathrm{~min}$, it was relative no additional sorbed $\mathrm{Au}$ (III) on sorbent (AMS and QAMS), so it can be argued that the sorption has reached equilibrium.

Considering the sorption of $\mathrm{Au}(\mathrm{III})$ on sorbent is an equilibrium process as same as an initial model to derive the Langmuir isotherm model illustrated below:

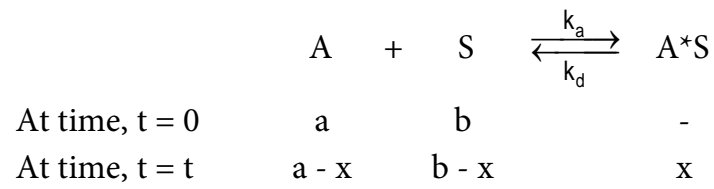


where $\mathrm{A}$ is a metal $\mathrm{Au}(\mathrm{III})$ or another metal; $\mathrm{S}$ is a sorbent (AMS and QAMS); $k_{a}$ is the sorption rate constant and $k_{d}$ desorption rate constant.

If $\mathrm{a}$ is the initial concentration of metal $\mathrm{A}(\mathrm{mol} / \mathrm{L}), \mathrm{b}$ is the Langmuir sorption capacity $(\mathrm{mol} / \mathrm{L})$, and $\mathrm{x}$ is the number of $\mathrm{A}$ is adsorbed on the $\mathrm{S}(\mathrm{mol} / \mathrm{L})$, so the equation rate can be written:

$\mathrm{r}_{\mathrm{ads}}=\frac{\mathrm{dx}}{\mathrm{dt}}=\mathrm{k}_{\mathrm{a}}(\mathrm{a}-\mathrm{x})(\mathrm{b}-\mathrm{x})-\mathrm{k}_{\mathrm{d}} \mathrm{x}$

After integration Eq. (4) generate new kinetics model known as RBS kinetics model, Eq. (5) which previously studied:

$\ln \left(\frac{\mathrm{ab}-\mathrm{x}_{\mathrm{e}} \mathrm{x}}{\mathrm{x}_{\mathrm{e}}-\mathrm{x}}\right)=\mathrm{k}_{\mathrm{a}}\left(\frac{\mathrm{ab}-\mathrm{x}_{\mathrm{e}}^{2}}{\mathrm{x}_{\mathrm{e}}}\right) \mathrm{t}-\ln \left(\frac{\mathrm{x}_{\mathrm{e}}}{\mathrm{ab}}\right)$
In this work, sorption rate of $\mathrm{Au}(\mathrm{III})$ onto AMS and QASM was studied by

Pseudo-first Order Lagergren: $\ln \left(\mathrm{x}_{\mathrm{e}}-\mathrm{x}\right)=\ln \mathrm{x}_{\mathrm{e}}-\mathrm{k}_{\text {lag }} \mathrm{t}$;

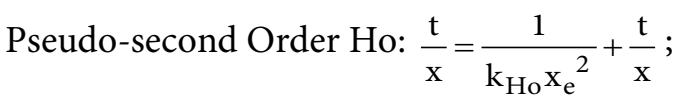

and RBS kinetics model which was previously worked by Rusdiarso et al. on sorption $\mathrm{Zn}^{2+}$ onto horse dung humic acid [10]. Application of these three kinetics model shows in Table 4. From the linearity, we can see that RBS kinetics model was the most suitable which represent the real system. It shows that the sorption rate constant $\left(\mathrm{k}_{\mathrm{a}}\right)$ of QAMS $\left(77.29 \mathrm{~min}^{-1}(\mathrm{~mole} / \mathrm{L})^{-1}\right)$ was higher than AMS (69.22 $\left.\mathrm{min}^{-1}(\mathrm{~mole} / \mathrm{L})^{-1}\right)$ and the desorption rate constant $\left(k_{d}\right)$ of QAMS $\left(4.74 \times 10^{-3} \mathrm{~min}^{-1}\right)$ was lower than

Table 4. Linearity and sorption rate parameter of sorption $200 \mathrm{mg}$ sorbents on sorption $100 \mathrm{~mL} \mathrm{Au}$ (III) $100 \mathrm{mg} \mathrm{L^{-1 }}$ in $\mathrm{pH} 5.0$ at $27^{\circ} \mathrm{C}$

\begin{tabular}{ccccccccc}
\hline \multirow{2}{*}{ Materials } & \multicolumn{2}{c}{ Lagergren } & \multicolumn{2}{c}{ Ho } & \multicolumn{3}{c}{$\mathrm{RBS}$} \\
\cline { 2 - 8 } & $\mathrm{R}^{2}$ & $\mathrm{k}_{\mathrm{lag}}\left(\mathrm{min}^{-1}\right)$ & $\mathrm{R}^{2}$ & $\mathrm{k}_{\mathrm{Ho}}\left(\mathrm{min}^{-1} \mathrm{~mol}^{-1} \mathrm{~L}\right)$ & $\mathrm{R}^{2}$ & $\mathrm{k}_{\mathrm{a}}\left(\mathrm{min}^{-1} \mathrm{~mol}^{-1} \mathrm{~L}\right)$ & $\mathrm{k}_{\mathrm{d}} \times 10^{-3}\left(\mathrm{~min}^{-1}\right) \mathrm{k}_{\mathrm{a}} / \mathrm{k}_{\mathrm{d}}\left(\mathrm{mol}^{-1} \mathrm{~L}\right)$ \\
\hline AMS & 0.938 & 0.0574 & 0.941 & 69.67 & 0.985 & 69.22 & 10.37 & 6676 \\
QAMS & 0.938 & 0.0620 & 0.970 & 59.93 & 0.988 & 77.29 & 4.74 & 16308 \\
\hline
\end{tabular}

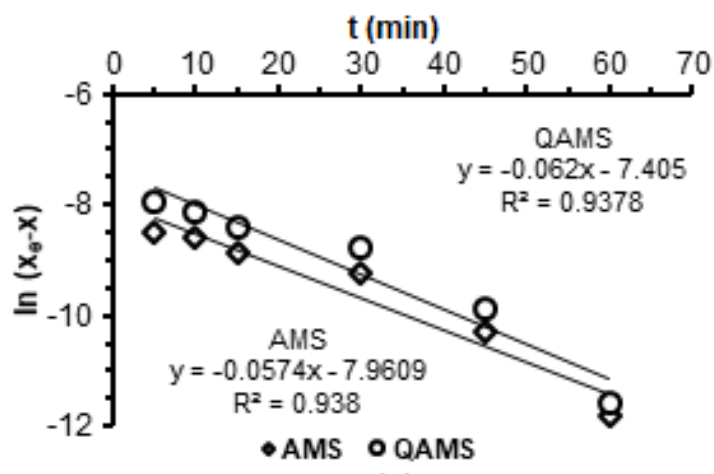

(a)

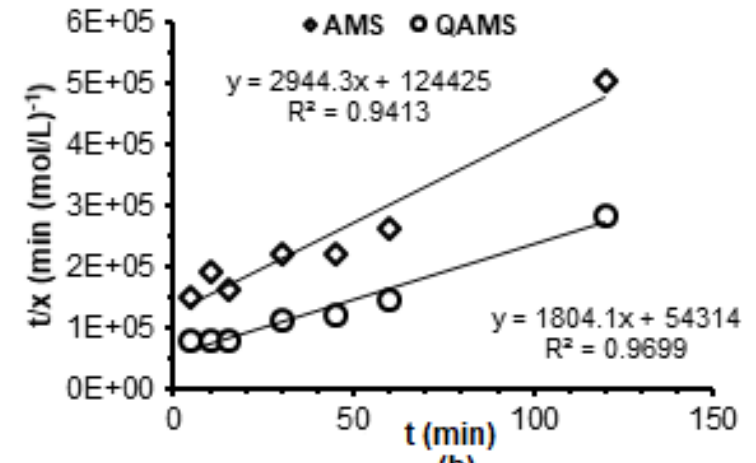

(b)

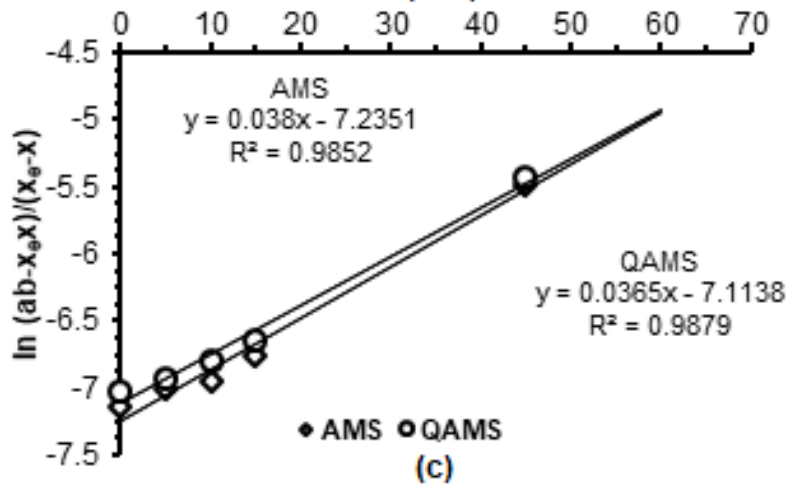

Fig 8. The linearity of Pseudo-first Order Lagergren (a), Pseudo-second Order Ho (b), and RBS kinetics model (c) of 100 $\mathrm{mL} \mathrm{Au}$ (III) $100 \mathrm{mg} / \mathrm{L}$ sorption onto $0.2 \mathrm{~g}$ AMS $(\mathrm{pH}=3)$ and $0.2 \mathrm{~g}$ QAMS $(\mathrm{pH}=5)$ 
AMS $\left(10.37 \times 10^{-3} \mathrm{~min}^{-1}\right)$. These numbers indicate that $\mathrm{Au}(\mathrm{III})$ was sorbed faster on QAMS than on AMS; however, after it was sorbed, QAMS had the stronger interaction with $\mathrm{Au}$ (III) compare with $\mathrm{Au}$ (III) with QAMS. This strong interaction might be caused by reinforcement of active site of QAMS due to increasing interaction resulted from 3 methyl group addition. The sorption energy also proved that sorption energy of QAMS was higher than AMS.

The RBS kinetics model was derived from the same models generated by Langmuir isotherm model, so the parameters of these equations should be related. The value of equilibrium constant $\left(\mathrm{K}_{\mathrm{L}}\right)$ from Langmuir was $14491(\mathrm{~mole} / \mathrm{L})^{-1}$ and $14809(\mathrm{~mole} / \mathrm{L})^{-1}$ for AMS and QAMS, respectively. From RBS kinetic model, $\mathrm{K}_{\mathrm{RBS}}$ was counted as $k_{a} / k_{d}$. The value of $K_{R B S}$ for AMS and QAMS was $6676(\mathrm{~mole} / \mathrm{L})^{-1}$ and 16309 (mole/L) $)^{-1}$, respectively. The value of $K_{R B S}$ and $K_{L}$ of QAMS had almost similar magnitude compared to the value of $K_{R B S}$ and $K_{L}$ of AMS.

From our previous work, there was a strong relationship between the condition of the initial concentration of sorbate (a) and the sorption capacity (b). If the ratio of $\mathrm{a}$ and $\mathrm{b}$ is relatively equal, the Pseudosecond order Ho tend to have good linearity, oppositely if a are much higher than b, Pseudo-first Order Lagergren and RBS kinetics models tend to have good linearity [10]. Langmuir isotherm study (Table 4) show that there was increasing of sorption capacity of AMS (37.94 $\left.\mathrm{mg} \mathrm{g}^{-1}\right)$ to QAMS (74.47 $\mathrm{mg} \mathrm{g}^{-1}$ ) on $\mathrm{Au}(\mathrm{III})$ sorption. This kinetics work applied $0.2 \mathrm{~g}$ of sorbents on sorption of $100 \mathrm{~mL}$ $\mathrm{Au}$ (III) $100 \mathrm{mg} \mathrm{L}^{-1}$ so that the ratio of a:b can be calculated in mole/L unit ( $\mathrm{Ar} \mathrm{Au}=196.97)$. The ratio of $\mathrm{a}: \mathrm{b}$ of AMS was $5.077 \times 10^{-4}: 3.852 \times 10^{-4} \approx 4: 3$. Addition of three methyl groups to AMS to form QAMS increased the sorption capacity so that the ratio will be $5.077 \times 10^{-4}: 7.562 \times 10^{-4} \approx 4: 6$. The change from AMS to QAMS has been practically rising the sorption capacity twice that affected to the value of sorption rate constant $\left(k_{\mathrm{a}}\right)$ and desorption rate constant $\left(\mathrm{k}_{\mathrm{d}}\right)$.

The change of $k_{a}$ and $k_{d}$ will lead to the change of comparison on these $\mathrm{K}_{\mathrm{RBS}}$ and $\mathrm{K}_{\mathrm{L}}$. The linearity of kinetics models Sorption energy, E generated from calculation Langmuir data $\mathrm{E}=-\mathrm{RT} \ln \mathrm{K}$ of AMS and QAMS was
$23.90 \mathrm{~kJ} / \mathrm{mole}$ and $23.95 \mathrm{~kJ} / \mathrm{mole}$, respectively. Sorption energy from calculation $\mathrm{E}=-\mathrm{RT} \ln \left(\mathrm{k}_{\mathrm{a}} / \mathrm{k}_{\mathrm{d}}\right)$ was quite close -especially for QAMS- from that was 21.95 $\mathrm{kJ} / \mathrm{mole}$ and $24.19 \mathrm{~kJ} / \mathrm{mole}$ for AMS and QAMS, respectively. All these relations of kinetics data and isotherm data proved that they are connected in a certain condition (ratio between initial concentration (a) and sorption capacity (b) from Langmuir isotherm model).

\section{- CONCLUSION}

It was successfully proved that the addition of three methyl group on AMS to formed QAMS would change the sorption characteristic of the material. This change increased the specific surface area, total pore volume, and pore diameter, without destroying the crystal structure. The optimum $\mathrm{pH}$ of $\mathrm{Au}(\mathrm{III})$ sorption shifted from 3 (AMS) to 5 (QAMS), where it has many advantages in sorption of $\mathrm{Au}(\mathrm{III})$. The sorption capacity of QAMS increased approximately twice and exceeded the sorption capacity of several previous researchers on $\mathrm{Au}(\mathrm{III})$ sorption. The increase in rate sorption of $\mathrm{Au}(\mathrm{III})$ on QAMS indicated that QAMS have the stronger interaction with $\mathrm{Au}(\mathrm{III})$ than AMS.

\section{- ACKNOWLEDGMENTS}

This work was supported by Ministry of Research and Higher Education through Competitive Grants Research Program, contract number: 283.UP21.17/PP/ 2017. The authors thank for financing this work.

\section{- REFERENCES}

[1] Wan Ngah, W.S., and Liang, K.H., 1999, Adsorption of gold(III) ions onto chitosan and $\mathrm{N}$ carboxymethyl chitosan: Equilibrium studies, Ind. Eng. Chem. Res., 38 (4), 1411-1414.

[2] Ramesh, A., Hasegawa, H., Sugimoto, W., Maki, T., and Ueda, K., 2008, Adsorption of gold(III), platinum(IV) and palladium(II) onto glycine modified cross linked chitosan resin, Bioresour Technol., 99 (9), 3801-3809.

[3] Morcali, M.H., Zeytuncu, B., Akman, S., and Yucel, O., 2014, Sorption of gold from electronic waste solutions by a commercial sorbent, Chem. Eng. Commun., 201 (8), 1041-1053. 
[4] Dwivedi, A.D., Dubey, S.P., Hokkanen, S., Fallah, R.N., and Silanpää, M., 2014, Recovery of gold from aqueous solutions by taurine modified cellulose: An adsorptive-reduction pathway, Chem. Eng. J., 255, 97-106.

[5] Foo, K.Y., and Hameed, B.H., 2010, Insights into the modeling of adsorption isotherm systems, Chem. Eng. J., 156 (1), 2-10.

[6] Hastuti, S., Nuryono, and Kuncaka, A., 2015, Larginine-modified silica for adsorption of gold(III), Indones. J. Chem., 15 (2), 108-115.

[7] Buhani, Narsito, Nuryono, Kunarti, E.S., and Suharso, 2014, Adsorption competition of $\mathrm{Cu}$ (II) ion in ionic pair and multi-metal solution by ionic imprinted amino-silica hybrid adsorbent, Desalin. Water Treat., 55 (5), 1240-1252.

[8] Anastopolous, I., and Kyzas, G.Z., 2016, Are the thermodynamic parameters correctly estimated in liquid-phase adsorption phenomena?, J. Mol. Liq., $218,174-185$.

[9] Langmuir, I., 1918, Adsorption gases on plane surface of glass, mica, and platinum, J. Am. Chem. Soc., 40 (9), 1361-1403.

[10] Rusdiarso, B., Basuki, R., and Santosa, S.J., 2016, Evaluation of Lagergren kinetics expression of sorption of $\mathrm{Zn}^{2+}$ onto horse dung humic acid (HDHA), Indones. J. Chem., 16 (3), 338-346.

[11] Freundlich, H., 1906, Adsorption in Solution, $Z$. Phys. Chem., 57, 384-410.

[12] Lagergren, S., 1898, About the Theory of So-called Adsorption of Soluble Substance, Kungl. Sven. Vetenskapsakad. Handl., 24 (4), 1-39.

[13] Ho, Y., and McKay, G., 1999, Pseudo second order model for sorption process, Process Biochem., 34 (5), 451-465.
[14] Sarawade, P.B., Kim, J.K., Hilonga, A., Quang, D.V., Jeon, S.J., and Kim, H.T., 2011, Synthesis of sodium silicate-based hydrophilic silica aerogel beads with superior properties: Effect of heat-treatment, $J$. Non-Cryst. Solids, 357 (10), 2156-2162.

[15] Chen, A.H., Liu, S.C., Chen, C.Y., and Chen, C.Y., 2008, Comparative adsorption of $\mathrm{Cu}(\mathrm{II}), \mathrm{Zn}(\mathrm{II})$ and $\mathrm{Pb}$ (II) ions in aqueous solution on the crosslinked chitosan with epichlorohydrin, J. Hazard. Mater., 154 (1-3), 184-191.

[16] Kalapathy, U., Proctor, A., and Shultz, J., 2000, A simple method for production of pure silica from rice hull ash, Bioresour. Technol., 73 (3), 257-262.

[17] Kalapathy, U., Proctor, A., and Shultz, J., 2002, An improved method for production of silica from rice hull ash, Bioresour. Technol., 85 (3), 285-289.

[18] Kalapathy, U., Proctor, A., and Shultz, J., 2003, Silicate thermal insulation material from rice hull ash, Ind. Eng. Chem. Res., 42 (1), 46-49.

[19] Della, V.P., Kühn, I., and Hotza, D., 2002, Rice husk ash as a source for active silica production, Mater. Lett., 57 (4), 818-821.

[20] Yu, Y., Yaddai-Mensah, J., and Losic, D., 2011, Chemical functionalization of diatom silica microparticles for adsorption of gold(III) ions, $J$. Nanosci. Nanotechnol., 11 (12), 10349-10356.

[21] Fujiwara, K., Ramesh, A., Maki, T., Hasegawa, H., and Ueda, K., 2007, Adsorption of platinum(IV) palladium(II) and gold(III) from aqueous solution onto l-lysine modified crosslinked chitosan resin, $J$. Hazard Mater., 146 (1-2), 39-50.

[22] Wang, H., Bao, C., Li, F., Kong, X., and Xu, J., 2010, Preparation and application of 4-amino-4'-nitro azobenzene modified chitosan as a selective adsorbent for the determination of $\mathrm{Au}(\mathrm{III})$ and Pd(II), Microchim. Acta, 168 (1-2), 99-100. 